\title{
Probing the regulatory effects of specific mutations in three major binding domains of the pleiotropic regulator CcpA of Bacillus subtilis
}

\author{
Ruud Detert Oude Weme ${ }^{1}$, Gerald Seidel ${ }^{2}$ and Oscar P. Kuipers ${ }^{1 *}$ \\ ${ }^{1}$ Molecular Genetics Group, Groningen Biomolecular Sciences and Biotechnology Institute, University of Groningen, \\ Groningen, Netherlands, ${ }^{2}$ Lehrstuhl für Mikrobiologie, Institut für Mikrobiologie, Biochemie und Genetik der \\ Friedrich-Alexander Universität Erlangen-Nürnberg, Erlangen, Germany
}

OPEN ACCESS

Edited by:

Eric Altermann,

AgResearch Ltd, New Zealand

Reviewed by:

Hua Xiang,

Institute of Microbiology, China

Jörg Stülke,

Georg-August-Universität Göttingen,

Germany

*Correspondence:

Oscar P. Kuipers,

Groningen Biomolecular Sciences and Biotechnology Institute, University of Groningen, Nijenborgh 7, 9747 AG

Groningen, Netherlands

o.p.kuipers@rug.nl

Specialty section: This article was submitted to

Evolutionary and Genomic Microbiology,

a section of the journal Frontiers in Microbiology

Received: 01 July 2015 Accepted: 14 September 2015 Published: 02 October 2015

Citation:

Detert Oude Weme R, Seidel G and

Kuipers OP (2015) Probing the regulatory effects of specific mutations in three major binding domains of the pleiotropic regulator CcpA of Bacillus subtilis. Front. Microbiol. 6:1051. doi: 10.3389/fmicb.2015.01051
Carbon catabolite control is required for efficient use of available carbon sources to ensure rapid growth of bacteria. CcpA is a global regulator of carbon metabolism in Gram-positive bacteria like Bacillus subtilis. In this study the genome-wide gene regulation of a CcpA knockout and three specific CcpA mutants were studied by transcriptome analysis, to further elucidate the function of specific binding sites in CcpA. The following three amino acids were mutated to characterize their function: M17(R) which is involved in DNA binding, T62 $(\mathrm{H})$ which is important for the allosteric switch in CcpA upon HPr-Ser46-P binding, and R304(W) which is important for binding of the coeffectors HPr-Ser46-P and fructose-1,6-bisphosphate. The results confirm that CcpA was also involved in gene regulation in the absence of glucose. CcpA-M17R showed a small relief of Carbon Catabolite Control; the CcpA-M17R mutant regulates fewer genes than the CcpA-wt and the palindromicity of the cre site is less important for CcpA-M17R. CcpA-T62H was a stronger repressor than CcpA-wt and also acted as a strong repressor in the absence of glucose. CcpA-R304W was shown here to be less dependent on HPr-Ser46-P for its carbon catabolite control activities. The results presented here provide detailed information on alterations in gene regulation for each CcpA-mutant.

Keywords: CcpA, CcpA mutants, Bacillus subtilis, DNA microarray, transcriptomics

\section{Introduction}

Gram-negative and Gram-positive bacteria employ a mechanism called carbon catabolite control (CCC) to use carbon sources in a preferential manner (Stülke and Hillen, 2000; Görke and Stülke, 2008; Fujita, 2009). This mechanism ensures optimal use of the available nutrients and results in a fitness advantage in a natural environment. The Gram-positive bacterium Bacillus subtilis uses a global transcriptional regulator, carbon catabolite protein A (CcpA), to employ CCC. Together with the seryl phosphorylated form of the histidine-containing protein, HPr, are the main coeffector for transcriptional regulation of various operons, it is involved in regulation of carbon utilization, overflow metabolism, amino acid anabolism and nitrogen assimilation (Sonenshein, 2007; Deutscher, 2008; Görke and Stülke, 2008; Fujita, 2009). HPr is a phosphocarrier protein from the phosphotransferase system (PTS) transferring phosphoryl groups from its 
histidine 15 residue to EIIA enabling specific sugar transport by EII complexes. The regulatory function of HPr is initiated when a preferred carbon source like glucose is metabolized and the intracellular concentration of fructose-1,6-bisphosphate (FBP) increases. FBP stimulates the HPr kinase/phosphatase (HPrK/P), which phosphorylates HPr at serine 46 and thereby converting HPr into the CcpA-binding form (Schumacher et al., 2007; Görke and Stülke, 2008; Fujita, 2009). Additionally, HPrSer46P-CcpA complex formation can be stimulated by glucose-6phosphate (G6P) and (FBP) (Görke and Stülke, 2008; Fujita, 2009). Moreover, there is a second protein effector: the catabolite responsive $\mathrm{HPr}(\mathrm{Crh})$ that binds CcpA at the same site as $\mathrm{HPr}$ Ser46-P when Crh is phosphorylated at serine 46 by HPrK/P (Schumacher et al., 2006). The binding of HPr-Ser46-P to CcpA triggers an allosteric switch in CcpA allowing CcpA to bind its cognate DNA sequences, the catabolite responsive elements (cre) (Stülke and Hillen, 2000; Deutscher, 2008; Görke and Stülke, 2008). These cre sites are semi-palindromic sequences with the following consensus: WTGNNARCGNWWWCAW ( $\mathrm{R}$ is G or A, $\mathrm{W}$ is $\mathrm{A}$ or $\mathrm{T}$, and $\mathrm{N}$ is any base) (Miwa et al., 2000; Schumacher et al., 2011). After DNA binding CcpA can either act as a repressor, i.e., when the cre site is downstream of the promoter, (Carbon Catabolite Repression, CCR) or, in much fewer cases, as an activator, i.e., when the cre site is upstream of the promoter, (Carbon Catabolite Activation, CCA). However, there are also exceptions to this rule: the cre site of the levanase operon is upstream of the promoter but it is repressed by CcpA (MartinVerstraete et al., 1995). The expression of $10 \%$ of the genes in B. subtilis are affected by CcpA when glucose is present in the medium (Fujita, 2009), and the expression of $8 \%$ of the genes are affected in the absence of glucose (Moreno et al., 2001).

CcpA belongs to the LacI family (Henkin et al., 1991) and consists of an N-terminal DNA binding domain, and a Cterminal core protein containing the HPr-Ser46-P binding site, an effector binding cleft for G6P and FBP and a dimerization domain (Schumacher et al., 2007, 2011). The crystal structures of B. subtilis and B. megaterium CcpA-HPr-Ser46-P bound to different $c r e$ sites and structures of CcpA with FBP and G6P show which amino acids are important for DNA binding, for complex formation, and for coeffector binding (Schumacher et al., 2007, 2011). Studies of point mutations in CcpA, HPr, and Crh have contributed to elucidate the molecular function of several amino acids in the complex (Deutscher et al., 1994; Kuster-Schock et al., 1999; Horstmann et al., 2007; Sprehe et al., 2007). However, differential effects of distinct CcpA point mutations on CCR in vivo have also been found. This cannot be explained solely by a comparison of the available structures or interaction analyses because other regulators are also involved in gene regulation of carbon metabolism (e.g. regulon specific regulators such as RbsR).

In this study, we examined the regulons of specific CcpA mutants. Therefore, three specific amino acids in CcpA were mutated (Figure 1A) and examined by transcriptome analyses to study the effects on CCC. Two of these mutants, CcpAM17R and CcpA-R304W, have been shown in a previous study to differentially regulate $g n t R, x y n P$, alsS, and ackA (Sprehe et al., 2007). Interestingly, these mutants are located in different regions: M17 is in the DNA binding domain and contacts the cre site specifically, while R304 makes an important contact to the Ser46-P of HPr. The third mutant, CcpA-T62H was found to repress $x y n P$ very strongly in the absence of glucose (unpublished data). Threonine 62 is the last residue of the allosteric switch domain, mediating the signal of HPr-Ser46-P binding to the DNA binding domain (Schumacher et al., 2011). The aim of the transcriptome analysis presented here was to study the effect of the pointmutations on a genome-wide level and elucidate the mutant specific regulons. Furthermore we examined the presence of specific correlations between the deregulated or regulated genes and altered cre site binding. Will all genes and operons be affected equally by a specific mutation in CcpA or are some genes of the regulon more affected than others? This will provide novel insights on the importance of the residues M17, T62, and R304.
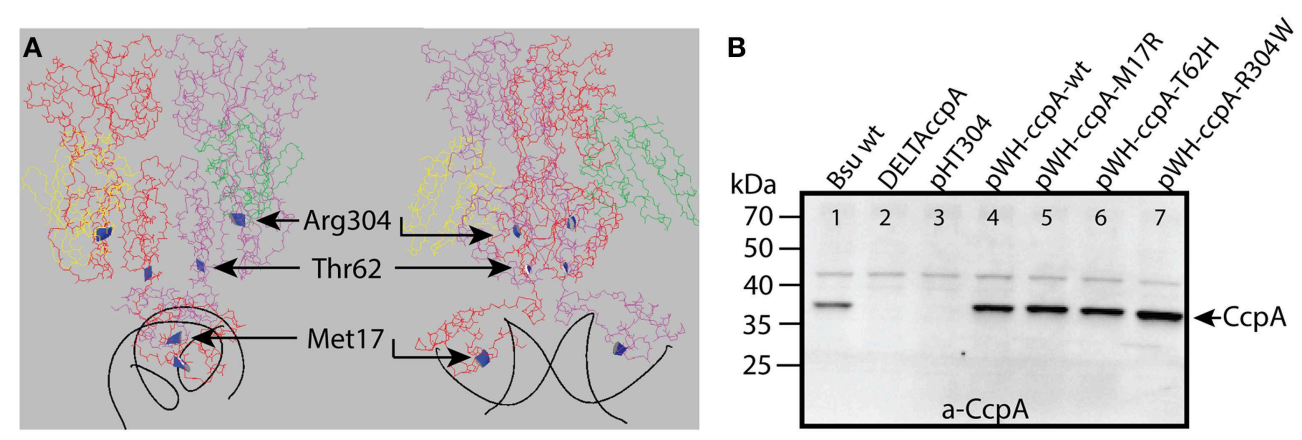

FIGURE 1 | (A) The crystal structure of CcpA-HPr-Ser46-P in complex with the AckA2-cre site, viewed along the DNA (left) and perpendicular to the DNA (right). The two CcpA monomers were shown in red and purple, the two HPr-Ser46-P monomers were shown in yellow and green, and the DNA was shown in black. The amino acids that were mutated in this study were highlighted in ribbon style in blue (adapted from PDB 30QM (Schumacher et al., 2011). (B) The expression levels of the different $\mathrm{CcpA}$ mutants were shown on a Western Blot. Crude extracts of the $B$. subtilis strains with the different $c c p A$ mutants were loaded on gel, transferred to a membrane and the CcpA proteins were visualized via chemiluminescence with a CcpA specific antibody. The size of the CcpA protein was 37 kDa. CcpA in lane 4-7 was expressed from plasmid. The B. subtilis cсpA::spec strain was utilized in lane $2-7$, and complemented with ccpA on the indicated pHT304 derived plasmid. The empty pHT304 vector served as negative control. 


\section{Materials and Methods}

Bacterial Strains, Plasmids, and Oligonucleotides B. subtilis $168 \operatorname{trpC2}$ strains (Table 1) were grown on Lysogeny Broth (LB). E. coli MC1061 was used as a cloning host. All plasmids are listed in Table 2 and the oligonucleotides in Table 3. The C-medium contains $70 \mathrm{mM} \mathrm{K}_{2} \mathrm{HPO}_{4}, 30 \mathrm{mM} \mathrm{KH}_{2} \mathrm{PO}_{4}$, $25 \mathrm{mM}\left(\mathrm{NH}_{4}\right)_{2} \mathrm{SO}_{4}, 0.5 \mathrm{mM} \mathrm{Mg}_{2} \mathrm{SO}_{4}, 10 \mu \mathrm{M} \mathrm{MnSO} \mathrm{H}_{4}, 22 \mathrm{mg} / \mathrm{l}$ Ferric Ammonium Citrate, $250 \mu \mathrm{M}$ L-Tryptophan, and $0.4 \%$ $(\mathrm{w} / \mathrm{v})$ glucose. C-medium supplemented with glutamate contains $0.03 \%(\mathrm{w} / \mathrm{v})$ L-Glutamate and when it was also supplemented with branched chain amino acids it contained $0.25 \%(\mathrm{w} / \mathrm{v})$ L-Isoleucine, $0.25 \%(\mathrm{w} / \mathrm{v})$ L-Leucine, $2.5 \%(\mathrm{w} / \mathrm{v})$ L-Valine, and $2.5 \%(\mathrm{w} / \mathrm{v})$ L-Methionine. Uridine $5^{\prime}$-monophosphate (Sigma) was added to C-medium in a final concentration of $20 \mathrm{mg} / \mathrm{l}$.

\section{Recombinant DNA Techniques}

PCR and DNA purification were done as previously described (Sambrook et al., 1989). Pfux7 DNA polymerase (Norholm, 2010) was a kind gift from Bert Poolman (University of Groningen), USER enzyme was obtained from New England Biolabs. Sequencing was done at MacroGen (Amsterdam, Netherlands).

TABLE 1 | B. subtilis strains used in this study.

\begin{tabular}{|c|c|c|}
\hline Strain & Genotype & Source or reference \\
\hline E. coli MC1061 & $\begin{array}{l}\mathrm{F}^{-} \text {araD139 } \Delta(\text { ara-leu)7696 galE15 } \\
\text { galK16 } \Delta\left(\text { lac)X74 hsdR2 }\left(\mathrm{r}_{\mathrm{K}}^{-} \mathrm{m}_{\mathrm{K}}^{+}\right) \text {mcrA }\right. \\
\text { mcrB1 rpsL (Strr) }\end{array}$ & $\begin{array}{l}\text { Laboratory stock, } \\
\text { (Casadaban and } \\
\text { Cohen, 1980) }\end{array}$ \\
\hline \multicolumn{3}{|l|}{ B. SUBTILIS } \\
\hline 168 & $\operatorname{trpC2}$ & $\begin{array}{l}\text { Bacillus Genetic Stock } \\
\text { Center, (Zeigler et al., } \\
\text { 2008) }\end{array}$ \\
\hline DOW41 & $\operatorname{trpC2}$ cсpA::spec ${ }^{r}$ & This study \\
\hline DOW42 & DOW41 with pHT304 & This study \\
\hline DOW43 & DOW41 with $p W H 2422-c c p A-w t$ & This study \\
\hline DOW44 & DOW41 with $p W H 2422-c c p A-M 17 R$ & This study \\
\hline DOW45 & DOW41 with $p W H 2422-c c p A-T 62 H$ & This study \\
\hline DOW46 & DOW41 with pWH2422-cCpA-R304W & This study \\
\hline
\end{tabular}

TABLE 2 | The plasmids used in this study.

\begin{tabular}{lll}
\hline Plasmid & Genotype & Source or reference \\
\hline pUC18 & & NCBl accession number \\
& & L09136 \\
pUC18- $\triangle c c p A$ & Amp $^{r}$ aroA Spec ${ }^{r} y t x D$ & This study \\
pHT304 & & (Arantes and Lereclus, 1991) \\
pWH144-ccpA-T62H & pHT304 ccpAhis T62H & This study \\
pWH2422-ccpA-wt & pHT304 ccpA & This study (Arantes and \\
& & Lereclus, 1991) \\
pWH2422-ccpA-M17R & pHT304 ccpA-M17R & This study \\
pWH2422-ccpA-T62H & pHT304 ccpA-T62H & This study \\
pWH2422-ccpA-R304W & pHT304 ccpA-R304W & This study
\end{tabular}

\section{Construction of B. subtilis CcpA::spec}

The $B$. subtilis ccpA knockout strain was made by allelic replacement with a spectinomycin resistance gene. Therefore, $1000 \mathrm{bp}$ flanking regions of $\operatorname{ccp} A$ were amplified from the $B$. subtilis genome by PCR. The first flanking region was upstream of $c c p A$ (primers aroA_FW and aroA_REV) and the second flanking region was downstream of $\operatorname{ccp} A$ (primers $y t x D \_F W$ and $\left.y t x D \_R E V\right)$. PCR with Pfux7 as polymerase was also used to amplify pUC18 and the spectinomycin gene from pDOW01 (Detert Oude Weme et al., 2015) (see the primers in Table 3). Cloning of the DNA fragments (pUC18, aroA, $\operatorname{spec}^{\mathrm{r}}, y t x D$ ) was done using the uracil-excision DNA engineering method (Norholm, 2010). The ligation product, hereafter called pUC18$\triangle c c p A$, was transformed to E. coli. Plasmid sequence was confirmed by sequencing.

Natural competent B. subtilis (Harwood and Cutting, 1990) was transformed with pUC18- $\triangle c c p A$, which integrated into the native locus of $\operatorname{cp} A$, thereby replacing the $\operatorname{ccp} A$ gene by a spectinomycin ${ }^{\mathrm{r}}$ gene (strain DOW41 in Table 1). In the resulting ccpA knockout strain the region from 223 bp upstream till 1037 bp downstream of the $\operatorname{ccp} A$ translational start site was knocked out; the promoter and the $c c p A$ gene were deleted.

Colony PCR and PCR on isolated chromosomal DNA (with primers: spec_FW, spec_REV, ccpA_FW_check, ccpA_REV_check) were used to check whether the plasmid was inserted via double recombination and whether the $\operatorname{cpp} A$ gene was removed.

\section{Construction of the CcpA Mutant Strains}

All previous analyses of the CcpA mutants were done with C-terminally His-tagged CcpA, but the His-tag free plasmid pWH2422 was used here to rule out side-effects resulting from a His-Tag fused to CcpA. This plasmid carries wildtype $c c p A$ without a His-tag encoding region under control of its own

\begin{tabular}{|c|c|}
\hline Oligonucleotide & Sequence $\left(5^{\prime} \geq 3^{\prime}\right)$ \\
\hline pUC18_FW & AGAGTCGACCUGCAGGCATGCAAGCTTGG \\
\hline pUC18_REV & ATCCCCGGGTUCCGAGCTCGAATTC \\
\hline spec_FW & $\begin{array}{l}\text { AGCAAGCTUCACCTTTATGGTGAACGTAACGTGACTGGC } \\
\text { AAGAG }\end{array}$ \\
\hline spec_REV & AAGAAGATUACCAATTAGAATGAATATTTC \\
\hline$y t x D \_F W$ & AATCTTCTUGCTIIITCATGGGGAGAAATG \\
\hline$y t x D \_R E V$ & AGGTCGACTCUCTAAGCTTCATGTACAGATCCCTIIITG \\
\hline aroA_FW & TACCCGGGGAUAAAAAACCCTTGAACATTG \\
\hline aroA_REV & AAGCTTGCUAACGAGAAAGCATAAAAAAAG \\
\hline ccpA_FW_check & GACGGCATCGTGTTATGGG \\
\hline ccpA_REV_check & TCTATACGGTGCGGCAGTTC \\
\hline pUP19 & ATTAAGTTGGGTAACGCCAG \\
\hline pRev19 & TCGTATGTTGTGTGGAATTG \\
\hline ccpAmut1 & ATAATATCTAGAACCAAGTATACGTITCATC \\
\hline Blplin & ATAATAATAGCTCAGCTTATGACTTGGTTGACTITCTAAG \\
\hline BsuT62rand & ACCTACAGTSNNTGTTITIT \\
\hline hisbam & TATTATTATGGATCCTTAGCTTCCTTAGCTCCTGA \\
\hline
\end{tabular}


promoter and a lambda terminator downstream of the gene. For this purpose wildtype $c c p A$ was amplified from plasmid pWH144 (Horstmann et al., 2007) using the primer ccpAmutl and BlpIin, restricted with $\mathrm{XbaI}$ and $\mathrm{BlpI}$ and cloned into $\mathrm{pWH} 144$ yielding pWH2422. The plasmid pWH2422-ccpA-R304W was cloned analogously with a PCR fragment using the primer $c c p A$ mut 1 and BlpIin with the template pWH920 (Sprehe et al., 2007) carrying the mutant allele $c c p A-\mathrm{R} 304 \mathrm{~W}$. Plasmids pWH2422-ccpA-M17R and pWH2422-ccpA-T62H were subcloned in pWH2422 from pWH1541-ccpA-M17R (Sprehe et al., 2007) and pWH144-ccpA$\mathrm{T} 62 \mathrm{H}$ via the restriction sites $\mathrm{XbaI}$ and ClaI. Plasmid pWH144ccpA-T62 $\mathrm{H}$ was isolated from a plasmid pool of a randomization of T62. The randomization was done by a two-step PCR mutagenesis using the primers ccpAmut1, BsuT62rand, and hisbam.

Natural competent B. subtilis ccpA::spec (strain DOW41 in Table 1) cells were transformed with the resulting pWH2422cсpA mutant plasmids as described before (Harwood and Cutting, 1990), and plated on LB-agar plates supplemented with $2 \mu \mathrm{g} / \mathrm{ml}$ erythromycin. Colonies were checked for plasmid integrity with primers pUP19 and pRev19.

\section{DNA Microarray Analyses}

Lysogeny Broth (LB), supplemented with $2 \mu \mathrm{g} / \mathrm{ml}$ erythromycin when necessary, was inoculated with $B$. subtilis $168 \operatorname{trp} C 2$ strains from $-80^{\circ} \mathrm{C}$ and grown overnight at $200 \mathrm{rpm}$ at $37^{\circ} \mathrm{C}$. Next morning, the cells were diluted to an $\mathrm{OD}_{600}$ of 0.04 in fresh $\mathrm{LB}$ with $2 \mu \mathrm{g} / \mathrm{ml}$ erythromycin and $1 \%(\mathrm{w} / \mathrm{v})$ glucose and grown at $200 \mathrm{rpm}$ and $37^{\circ} \mathrm{C}$ until the $\mathrm{OD}_{600}$ was 0.3 . Now $100 \mathrm{ml}$ of cell culture was harvested by centrifugation ( $6000 \mathrm{rpm}, 5 \mathrm{~min}$ ) and used for RNA isolation. Cell pellets were resuspended in $400 \mu \mathrm{l}$ TE (DEPC) buffer, and transferred to screw-cap tubes with $0.5 \mathrm{~g}$ glass beads (<106 microns, Sigma), $50 \mu 1$ 10\% SDS and $500 \mu \mathrm{l} \mathrm{phenol/chloroform:IAA} \mathrm{(a} \mathrm{1:1} \mathrm{pre-made} \mathrm{mixture} \mathrm{of}$ phenol acid and chloroform:IAA (24:1); from this mixture the organic phase was used). The screw-capped tubes were placed in a bead beater for two times $1 \mathrm{~min}$ to lyse the cells. Total RNA was isolated with the High Pure RNA Isolation Kit (Roche). The RNA concentration was measured with the NanoDrop (ND-1000 spectrophotometer, NanoDrop Technologies) and the quality was checked on a $1 \%$ agarose gel supplemented with $1 \%$ bleach.

Superscript III Reverse Transcriptase (Invitrogen) and $20 \mu \mathrm{g}$ of total RNA were used for cDNA synthesis as described before (Lulko et al., 2007). Aminoallyl labeled cDNA was labeled with DyLight550 or DyLight650 (Thermoscientific). Now cDNA from $B$. subtilis ccpA-wt cells and cDNA from $B$. subtilis ccpA-mutant cells were mixed in a 1:1 ratio and hybridized overnight on homemade DNA microarray aminosilane glass slides (Lulko et al., 2007). Hybridization of cDNA on home-made slides was done three times with cDNA from three independent experiments, and the third time the dyes were swapped (see the NCBI GEO submission GSE69575 for details).

Slides were washed, dried and scanned with a GenePix 4200AL scanner (Axon Instruments, CA, USA). The images of the scans were analyzed with ArrayPro4.5 (Media Cybernetics Inc., Md, USA).
Further analysis was done with PrePrep (van Hijum et al., 2003), Prep, PostPrep and Cyber-T (van Hijum et al., 2005) as described before (Lulko et al., 2007; Marciniak et al., 2012).

Bayes $p$-values were used to calculate the significance and average spot intensity values were used to calculate the fold change of gene expression as described before (Long et al., 2001; Marciniak et al., 2012). Results shown here are the average of two biological replicates and a technical replicate (dye-swap). Only genes with a Bayes $p$-value smaller than 0.001 and a fold change larger than 1.7 or smaller than -1.7 were used for further analysis.

The microarray data is available at the NCBI GEO database (http://www.ncbi.nlm.nih.gov/geo/) under accession number GSE69575.

\section{Western Blotting}

B. subtilis cells harboring the plasmids with a ccpA mutant were grown as described above. Two milliliters of cells were harvested by centrifugation ( $5 \mathrm{~min}, 10,000 \mathrm{rpm}$ ) at an $\mathrm{OD}_{600}$ of 0.3 . The pellets were resuspended in $200 \mu \mathrm{l} 50 \mathrm{mM}$ Tris- $\mathrm{Cl}$ pH 7.4, a spatula tip of glassbeads ( $<106$ microns, Sigma) was added and subsequently cells were lysed by mini-bead beating (two times $1 \mathrm{~min}$, Mini-Beadbeater-16, Biospec products). After centrifugation ( $5 \mathrm{~min}, 10,000 \mathrm{rpm}$ ) the supernatant was transferred to a clean tube. Total protein was measured with the DC Protein Assay (BioRad) to ensure that equal amounts of protein were used. $30 \mu \mathrm{l}$ of $2 \mathrm{x}$ SDS loading buffer was added to $20 \mathrm{mg}$ of total protein in a volume of $30 \mu \mathrm{l}$ and heated for $5 \mathrm{~min}$ at $90^{\circ} \mathrm{C}$ before loading on a $12 \%$ SDS-PAGE gel. After electrophoresis, the proteins were transferred to a PVDF membrane (60 min, $80 \mathrm{~mA})$. The PVDF membrane was incubated in PBST $+5 \%(\mathrm{w} / \mathrm{v})$ skim milk at $4^{\circ} \mathrm{C}$ overnight. Next morning, the PVDF membrane was washed three times $10 \mathrm{~min}$ with PBST and subsequently incubated at room temperature for $2 \mathrm{~h}$ in PBST $+5 \%$ skim milk $+1: 10,000$ dilution of antiCcpA antibody (Kuster et al., 1996). The membrane was again washed three times $10 \mathrm{~min}$ with PBST and then incubated $1.5 \mathrm{~h}$ in PBST + goat-anti-rabbit Ig-horseradish peroxidase (Amersham Biosciences) at room temperature. Now the membrane was washed two times $10 \mathrm{~min}$ with PBST. $2 \mathrm{ml}$ of ECL detection reagent (GE Healthcare) and the Molecular Imager ChemiDoc $\mathrm{XRS}+($ BioRad) were used for signal visualization.

\section{Results}

\section{Expression Levels of the CcpA Mutant Proteins}

The expression levels of the different CcpA proteins were verified by Western blotting with anti-CcpA antibody before starting with the transcriptome analysis. Therefore, cell free extracts from $B$. subtilis harboring the plasmids with the $\operatorname{ccp} A$ mutants were loaded on a SDS-PAGE gel, transferred to a membrane and incubated with anti-CcpA antibody (Figure 1B). The DC Protein Assay (BioRad) was used to measure the total protein concentration in the cell free extract; this was used to ensure loading equal amounts of total protein on the gel. The $\operatorname{ccp} A$ on the pWH plasmid was expressed under the control of its native promoter, but despite the low copy number of the plasmid the amount of CcpA was higher than in wildtype B. subtilis 
(Figure 1B). The increase in CcpA expression from this plasmid has been observed before (Sprehe et al., 2007). The expression of the CcpA mutants from plasmid were all very similar, so the observed changes in gene expression in the microarray are most likely due to the mutation in CcpA and not due to changes in the expression level. No CcpA was detected in the ccpA knockout strain, indicating the successful removal of the gene (Figure 1B). An unspecific band around $45 \mathrm{kDa}$ was observed for all variants, which was not related to CcpA because it was also visible in the knockout strain and not related to the inserted plasmid because it was also visible in the wildtype strain.

The effects of the CcpA knockout and of the point mutations in the CcpA protein (M17R, T62H, or R304W) were studied on the transcriptome level at the early exponential growth phase $\left(\mathrm{OD}_{600}\right.$ of 0.3$)$ and always compared to the transcriptome of $B$. subtilis $p W H$-ccpA-wildtype. All strains were grown in LB, either in the presence or absence of $1 \%$ glucose. Our goal was to study whether all genes of the regulon will be up- or down-regulated equally or in a differential way. The results will be presented for each mutant separately in the sections below.

\section{The Gene Regulation of CcpA Knockout Compared to Wildtype CcpA}

The $c c p A$ knockout strain had an altered gene regulation for 216 genes when the strain was grown in LB $+1 \%$ glucose (Table 5, Supplementary File, Sheets 1-3). There is a large variety in the fold changes between the differentially regulated genes, confirming that the strength of transcriptional activation or repression by CcpA differs for each regulon. The expression of 189 of these genes was upregulated, confirming that CcpA mainly functions as a repressor. 61 of these 216 genes were members of the originally annotated CcpA regulon which consists of 213 genes (Mäder et al., 2012; Subtiwiki, 2014). The CcpA regulon as listed in SubtiWiki has been compiled from different papers (personal communication with Jörg Stülke, Göttingen, Germany) and might also contain indirectly regulated genes. Categorizing these 216 genes into COGs showed that most genes were from the groups Energy production and conversion and Carbohydrate transport and metabolism (Figure 3). When the $с с p A$ knockout strain was grown in LB then the expression of 89 genes was changed (Table 5, Supplementary File, Sheets 4-6), of which 31 genes belong to the CcpA regulon as listed in SubtiWiki. 55 genes were more abundant now compared to CcpA-wt, showing that CcpA was still active in the absence of glucose because those 55 genes were repressed by CcpA-wt. Most genes can be categorized again in Energy production and conversion and Carbohydrate transport and metabolism (Figure 3). The findings from the $c c p A$ knockout strain served as a reference to interpret the results from the CcpA-mutants. Our main questions were: are the CcpAmutants more or less active in repression or activation than the wildtype? Are all genes affected to similar extents or in a differential way?

\section{The Gene Regulation of CcpA-M17R Compared to Wildtype CcpA}

Most likely CcpA-M17R lost part of its capacity to repress genes, as can be concluded from the large number of derepressed genes. The gene regulation of the CcpA-M17R mutant differed significantly from the $\triangle \mathrm{CcpA}$ mutant. Of the genes that were affected by CcpA-M17R 53\% differed from the genes that were affected in the $\triangle \mathrm{CcpA}$ strain (Figure 2A and Supplementary File, Sheet 2). The number of affected genes was smaller (Table 5) indicating that the function of the CcpA-M17R mutant was similar to the CcpA-wt, but with lowered affinity for most binding sites. When the CcpA-M17R mutant strain was grown in $\mathrm{LB}+1 \%$ glucose the gene regulation for 129 genes (115 up and 14 down) differed from CcpA-wt (Table 5, Supplementary File, Sheets 1-3). Only 27 of these genes belonged to the CcpA regulon from SubtiWiki. Especially genes from COG categories: [C] Energy production and conversion, [R] General function prediction, and $[\mathrm{T}]$ Signal transduction mechanisms showed a weaker regulation by CcpA-M17R (Figure 3).

When the CcpA-M17R mutant strain was grown on LB then 67 genes (38 up and 29 down) had a changed gene regulation compared to CcpA-wt (Table 5, Supplementary File, Sheets 4-6). Nineteen of these genes belonged to the CcpA
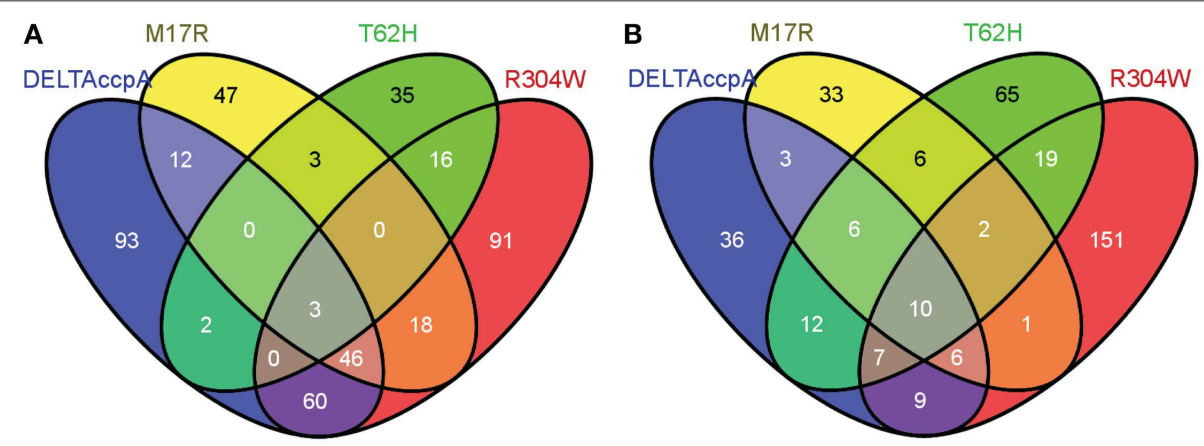

FIGURE 2 | Venn diagram showing the genes that were differentially regulated in each one of the CcpA mutant strains. Numbers represent the genes that were differentially regulated in each CcpA mutant strain. Only genes with a fold change larger than 1.7 or smaller than -1.7 were used in the analysis. (A) Overview of the differentially regulated genes when the strains with the CcpA mutant were grown on LB + 1\% glucose (see also Supplementary File, Sheet 2). (B) Overview of the differentially regulated genes when the strains with the CcpA mutant were grown on LB (see also Supplementary File, Sheet 5). Venn diagrams were made via http:// bioinfogp.cnb.csic.es/tools/venny/. More detailed information on up- or down-regulated genes is shown in Table 4. 


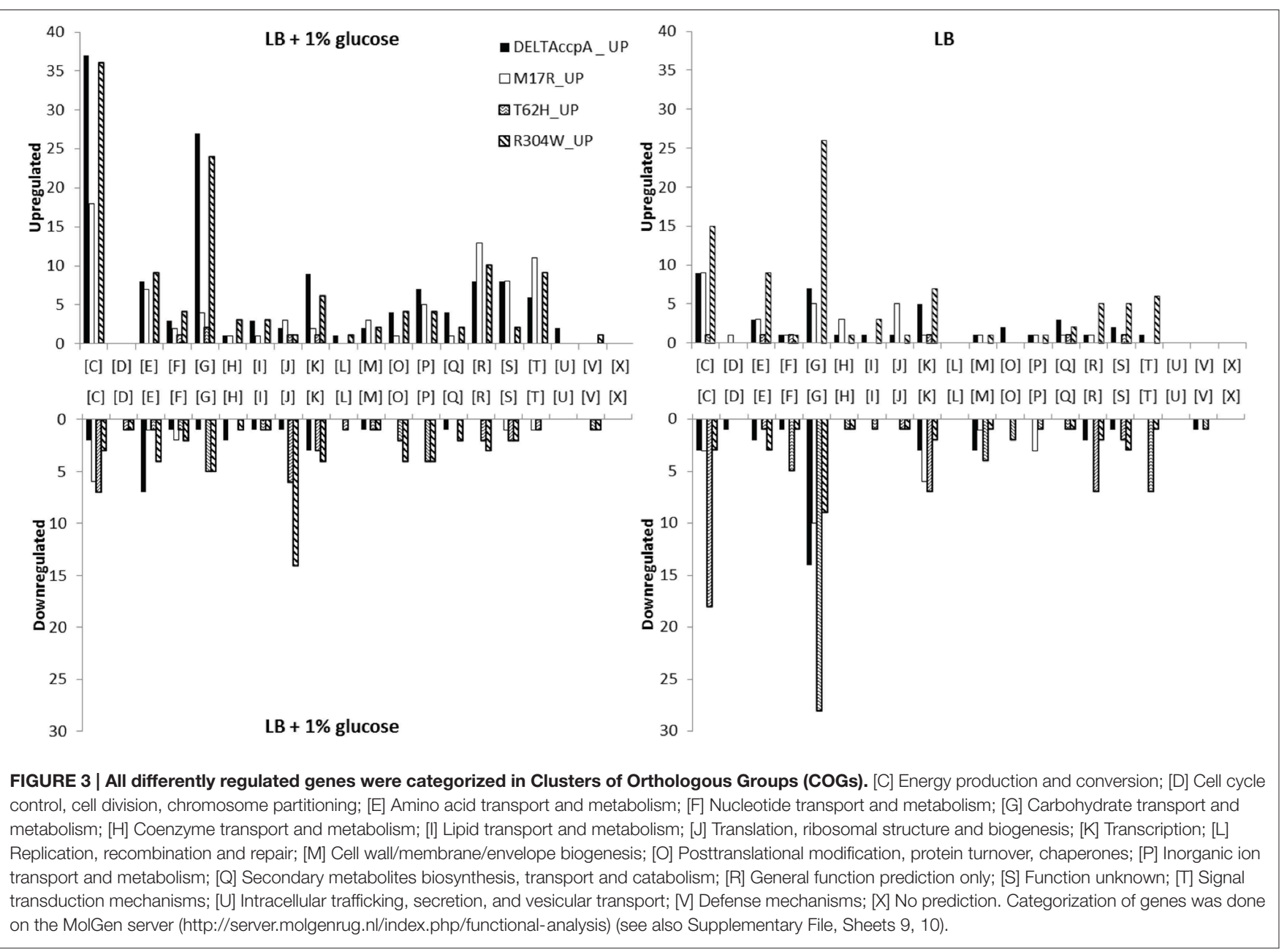

regulon from SubtiWiki. Mainly genes from COG categories: [C] Energy production and conversion, [G] Carbohydrate transport and metabolism, and [J] Translation, ribosomal structure and biogenesis showed a weaker regulation by CcpA-M17R (Figure 3). The uniquely affected genes for CcpA-M17R in LB with and without glucose are shown in Table 4.

\section{The Gene Regulation of CcpA-T62H Compared to Wildtype CcpA}

The CcpA-T62 is important for signal transduction from the HPr-Ser46-P interaction interface to the DNA binding domain (Schumacher et al., 2011). CcpA-T62H was found to be a stronger repressor. When the $\mathrm{CcpA}-\mathrm{T} 62 \mathrm{H}$ mutant strain was grown in $\mathrm{LB}+1 \%$ glucose then only 9 genes were upregulated, but 50 genes were repressed (Table 5, Supplementary File, Sheets 1-3). Only 5 of these 59 genes were also found in the $\Delta$ CcpA strain, the other 54 genes did not have an altered regulation in the $\triangle \mathrm{CcpA}$ strain (Figure 2A). The uniquely affected genes for CcpA-T62H are shown in Table 4. Genes from COG categories [C] Energy production and conversion, [G] Carbohydrate transport and metabolism, [J] Translation, ribosomal structure and biogenesis, and $[\mathrm{P}]$ Inorganic ion transport and metabolism showed a stronger regulation by $\mathrm{CcpA}-\mathrm{T} 62 \mathrm{H}$ (Figure 3 ). Only 3 of the 59 genes belonged to the CcpA regulon from SubtiWiki. When the CcpA-T62H strain was grown in LB without glucose then the regulatory effect of $\mathrm{CcpA}-\mathrm{T} 62 \mathrm{H}$ was even stronger than in LB $+1 \%$ glucose (Table 5, Supplementary File, Sheets 4-6). In LB without glucose there were 12 genes up- and 115 genes down-regulated (Figure 2B, Table 5, Supplementary File, Sheets $4,5)$ and 55 of them belonged to the CcpA regulon from SubtiWiki. Genes from COG categories [C] Energy production and conversion, [G] Carbohydrate transport and metabolism, [K] Transcription, [M] Cell wall/membrane/envelope biogenesis, [R] General function prediction only, and [T] Signal transduction mechanisms showed a stronger regulation by $\mathrm{CcpA}-\mathrm{T} 62 \mathrm{H}$ (Figure 3).

\section{The Gene Regulation of CcpA-R304W Compared to Wildtype CcpA}

The arginine on position 304 is important to contact the Ser46-P of HPr. We hypothesized that the CcpA-R304W had a reduced affinity for the glucose sensor protein HPr-Ser46-P but there is still a large number of affected genes (165 up and 69 down) when the strain was grown in LB $+1 \%$ glucose. 


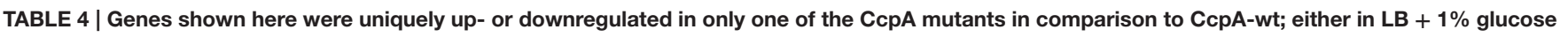
(left side) or in LB without glucose (right side).

\begin{tabular}{|c|c|c|c|c|c|c|c|c|c|c|c|c|}
\hline \multicolumn{6}{|c|}{ LB $+1 \%$ glucose } & \multicolumn{7}{|c|}{ LB without glucose } \\
\hline \multicolumn{2}{|c|}{ CcpA-M17R } & \multicolumn{2}{|c|}{ СсрА-Т62H } & \multicolumn{2}{|c|}{ CcpA-R304W } & \multicolumn{2}{|c|}{ CcpA-M17R } & \multicolumn{2}{|c|}{ СсрА-Т62H } & \multicolumn{3}{|c|}{ CcpA-R304W } \\
\hline \multicolumn{2}{|c|}{47} & \multicolumn{2}{|c|}{35} & \multicolumn{2}{|c|}{91} & \multicolumn{2}{|c|}{33} & \multicolumn{2}{|c|}{65} & \multicolumn{3}{|c|}{151} \\
\hline 43 & 4 & 8 & 27 & 42 & 49 & 22 & 11 & 9 & 56 & 112 & & 39 \\
\hline Up: & Down: & Up: & Down: & Up: & Down: & Up: & Down: & Up: & Down: & Up: & & Down: \\
\hline citT & glpD & $\operatorname{man} A$ & bdbB & acuA & abrB & flim & $\operatorname{cspB}$ & gltC & $\mathrm{aco} A$ & abfA & $y d z A$ & alsS \\
\hline ctc & pyrE & $\operatorname{manP}$ & $\operatorname{csfB}$ & ald & ahpF & glyQ & dacA & hag & $\mathrm{bdbA}$ & $\operatorname{acs} A$ & yesL & cgeA \\
\hline cydA & yckB & $\operatorname{manR}$ & dppC & amyE & aroE & hemC & feuA & ilvH & $\mathrm{bdbB}$ & amyE & yesM & $\operatorname{cotV}$ \\
\hline cydB & yqjE & pyrC & fhuD & ansB & cspB & icd & flgE & purQ & $\operatorname{csbA}$ & araB & yesN & $\operatorname{coxA}$ \\
\hline cydC & & yjdF & gudB & $\mathrm{bdbA}$ & cspC & lytB & glpP & ydcS & $\mathrm{csbC}$ & $\operatorname{araD}$ & yfiD & cwID \\
\hline gtaB & & yjdG & hbs & bofC & ctsR & mdh & pstC & yhfC & csbD & citM & yfiE & leuB \\
\hline gutR & & ynaF & IrpB & $\operatorname{dctP}$ & efp & oppD & yaaN & ykoL & dra & $\operatorname{csb} X$ & yfiH & leus \\
\hline icd & & yydJ & nagP & dhas & fabF & $\mathrm{pdhC}$ & yddT & yomL & etfA & cstA & $\mathrm{yfmN}$ & $\operatorname{nin}$ \\
\hline Idh & & & spooM & drm & frr & pgi & ydfF & ywnJ & etfB & ctaD & ygaO & opuE \\
\hline mcsA & & & sunA & etfB & $\mathrm{ftsH}$ & pgk & ydjM & & galT & $\operatorname{dctB}$ & yhaS & pta \\
\hline mcsB & & & ugtP & hemC & gltP & pgm & yybN & & glpF & $\operatorname{dctR}$ & yhax & sigE \\
\hline mrgA & & & ycnl & katE & leuD & rplE & & & gntP & fabHB & yhfW & spollIAC \\
\hline mrpB & & & ycnK & kdgK & maeN & rplF & & & gspA & $\mathrm{fbaB}$ & yisk & spoVAA \\
\hline оррA & & & yeeG & kdgT & $\mathrm{mntH}$ & rpsK & & & kipR & glpT & yjdB & ssb \\
\hline phrk & & & yezE & $\mathrm{mmsA}$ & rplQ & rpsS & & & melA & hutH & ykuN & ybcD \\
\hline smf & & & yfhC & narG & rpmB & tpiA & & & mleA & $h \times \mid A$ & $y k z A$ & $\mathrm{ybcH}$ \\
\hline spoOE & & & yfmQ & nupC & rpmF & yaaD & & & mleN & iolC & ykzE & ybcM \\
\hline treP & & & yhdN & punA & rpmGB & ykrS & & & nagP & iolH & yocF & yckE \\
\hline xpaC & & & yisQ & qcrA & $\mathrm{rpsO}$ & ykrT & & & ndk & ioll & yocG & $y c x C$ \\
\hline ydaD & & & yjbD & qoxB & rpsT & ylbQ & & & nhax & kbl & yomT & ydfR \\
\hline ydas & & & yjeA & recO & smpB & yvfV & & & nupC & kdgA & yomZ & ydje \\
\hline ydaT & & & yjmF & resA & sspE & yvzB & & & odhA & kdgK & yonE & yesS \\
\hline$y d b D$ & & & ylqC & resB & yabR & & & & odhB & kdgT & yonH & yezD \\
\hline ydhK & & & yodC & resC & ybaR & & & & pdp & $\operatorname{lac} A$ & yonk & yfhC \\
\hline yebE & & & yoeB & resD & yccG & & & & rpsC & IcfA & yopY & yhcA \\
\hline yfhD & & & yozB & resE & yceJ & & & & rsbV & malL & yoqF & yhcB \\
\hline yfkJ & & & $y x k O$ & rocC & yczH & & & & rsbW & $m t \mid R$ & yoqs & yhcC \\
\hline yhzC & & & & rplF & ydaH & & & & rsbX & pel & yosB & yhjB \\
\hline yjcG & & & & sunT & ydgB & & & & sdhA & phrC & yosD & yitJ \\
\hline ykrS & & & & ydhP & $y d g F$ & & & & sdhB & qcrB & yosJ & yjbD \\
\hline yoqZ & & & & yfiD & ydhB & & & & sunT & qcrC & ypiF & yjeA \\
\hline yoxC & & & & yhfD & yebc & & & & treR & rocB & ypzC & yocN \\
\hline ytiA & & & & yolJ & yfjT & & & & ybyB & rocC & yqaD & yodC \\
\hline ytzE & & & & yoqx & yhbJ & & & & ydaG & sacB & yqck & yqas \\
\hline yuaF & & & & ypwA & yhcB & & & & ydhM & senS & yqkK & yqbM \\
\hline yual & & & & yraO & yjhB & & & & ydhT & spolllAH & yqzG & yurO \\
\hline yuiD & & & & yrkA & ykoA & & & & yfhD & sspO & yraO & yurP \\
\hline yvaA & & & & ysiA & ylaG & & & & yflT & tyrZ & yrhP & yutK \\
\hline ywfC & & & & $y t x E$ & yodJ & & & & yhaP & xepA & ytcP & yvgW \\
\hline ywmE & & & & yuxl & yqeY & & & & yolJ & $x h \mid B$ & yteQ & \\
\hline ywzA & & & & ywiE & yqjL & & & & yoxC & $\mathrm{xkdH}$ & ytll & \\
\hline yxiS & & & & ywmA & yrvM & & & & yqhA & $x k d K$ & yugM & \\
\hline \multirow[t]{2}{*}{$y x z F$} & & & & & yuiF & & & & yqhB & $x k d N$ & yugN & \\
\hline & & & & & yusG & & & & ysbA & $\mathrm{xkdO}$ & yukJ & \\
\hline
\end{tabular}


TABLE 4 | Continued

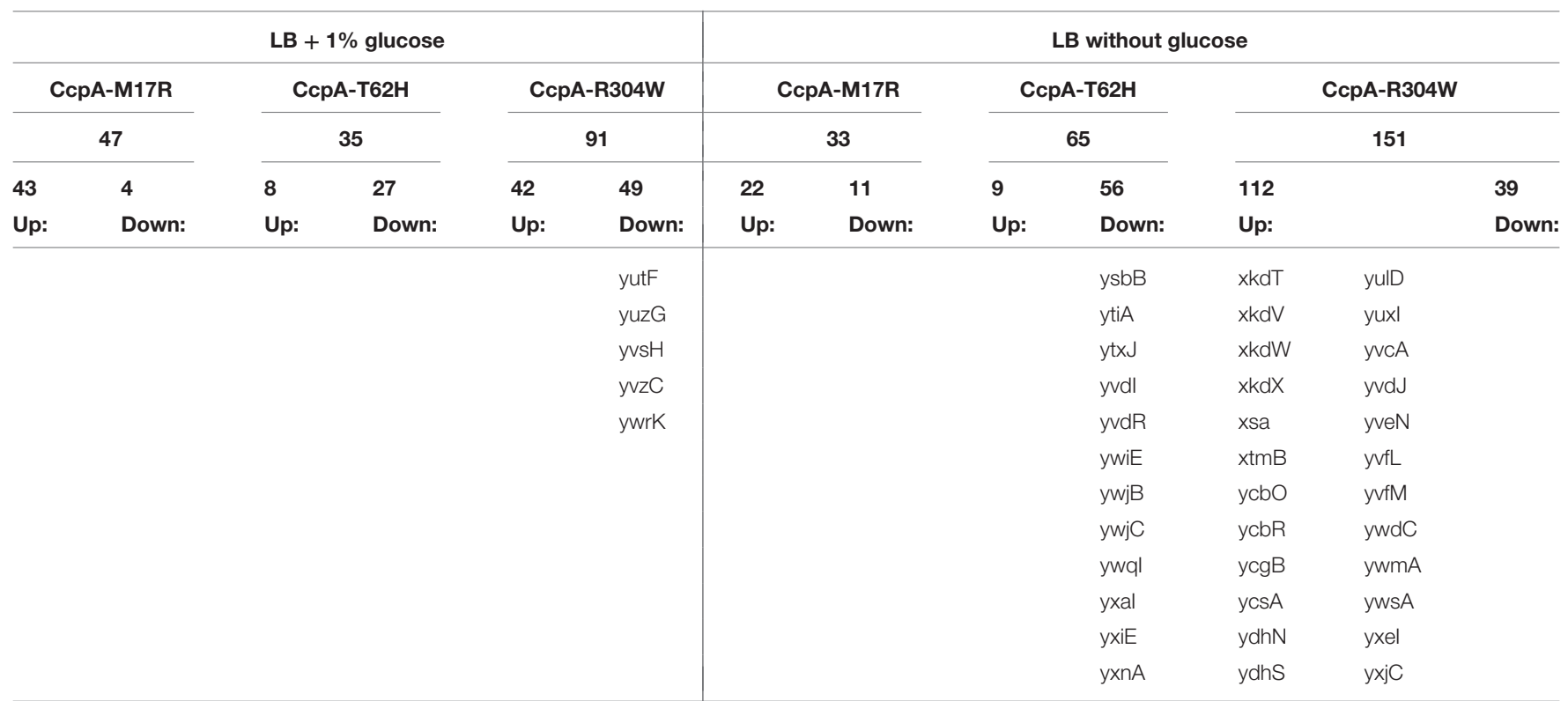

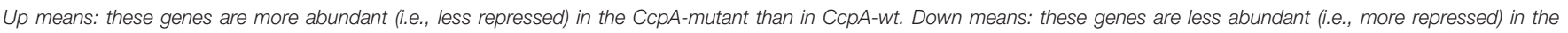
CсpA-mutant than in CсpA-wt. The numbers refer to Figures $\mathbf{2 A}, \mathbf{B}$ and represent the number of uniquely up- or down-regulated genes per CcpA-mutant.

TABLE 5 | The number of genes with altered regulation for each mutant compared to CcpA-wt as found in this transcriptomics study.

\begin{tabular}{lccccc}
\hline & \multicolumn{2}{c}{ LB $+\mathbf{1 \%}$ glucose } & & \multicolumn{2}{c}{ LB } \\
\cline { 2 - 3 } \cline { 5 - 6 } & Up & Down & & Up & Down \\
\hline ACcpA & 189 & 27 & & 55 & 34 \\
CcpA-M17R & 115 & 14 & & 38 & 29 \\
CcpA-T62H & 9 & 50 & & 12 & 115 \\
CcpA-R304W & 165 & 69 & & 155 & 51 \\
\hline
\end{tabular}

In total, 426 different genes had an altered regulation on $L B+1 \%$ glucose and 366 different genes had an altered regulation on LB without glucose (see also Figure 2).

When the CcpA-R304W strain was grown in the absence of glucose the number of affected genes was almost as high; there were 206 genes affected (155 up and 51 down) of which 151 genes were unique for CcpA-R304W (Figures 2A,B, Table 5 and Supplementary File, Sheets 4-6). Fifty nine of the affected genes in LB only belonged to the CcpA regulon from SubtiWiki. The overlap of CcpA-R304W with $\triangle \mathrm{CcpA}$ is much larger in the presence of glucose (109 genes), than in the absence of glucose (32 genes, compare Figures 2A,B) showing that the HPr dependent gene regulation of CcpA is disturbed, but not the HPr independent gene regulation of CcpA. Therefore, we can conclude that the role of HPr-Ser46-P is less pronounced for this mutant.

\section{Functional Analysis of the Affected Genes}

For a more detailed look on the differences between the CcpA mutants all genes with a different regulation were functionally analyzed by categorizing those genes into Clusters of Orthologous Groups (COGs) (Figure 3). When the cells were grown on $\mathrm{LB}+1 \%$ glucose then genes for energy production and conversion $[\mathrm{C}]$ were upregulated in all mutants, except for CcpA-T62H. Expression of genes for carbohydrate transport and metabolism [G] in $\triangle \mathrm{CcpA}$ and CcpA-R304W showed the most difference. CcpA-T62H and CcpA-R304W showed a down regulation of translation, ribosomal structure and biogenesis genes [J] (Figure 3, LB $+1 \%$ glucose). When the cells were grown on LB without glucose then the CcpA$\mathrm{T} 62 \mathrm{H}$ and CcpA-R304W strains had most differences in gene regulation for genes in energy production and conversion [C] and carbohydrate transport and metabolism [G] compared to CcpA-wt (Figure 3).

\section{Growth of the Strains with the CcpA Mutants on C-medium}

A $\operatorname{ccp} A$ knockout strain shows a growth defect in glucose minimal medium (Faires et al., 1999; Fujita, 2009). Here we tested how the CcpA mutant strains performed in glucose minimal medium. In the strains with the CcpA mutants, some genes coding for proteins responsible for amino acid catabolism were deregulated. One of them was the gene $\operatorname{roc} G$ coding for glutamate dehydrogenase. Normally, the $\operatorname{roc} G$ gene is repressed by CcpA, but in both growth conditions used in this study and in strains with all CcpA variants except CcpA-T62H, the repression of rocG was released. Higher levels of RocG decrease the level of glutamate, which impairs the growth of these strains on a glucose minimal medium (Fujita, 2009). The altered gene regulation of $\operatorname{roc} G$ caused a growth deficiency of the CcpA mutant strains on minimal medium, which was shown on C-medium agar plates for the strains with the $\triangle \mathrm{CcpA}$, CcpA-M17R, and CcpA-R304W mutations (Figure 4A). The 


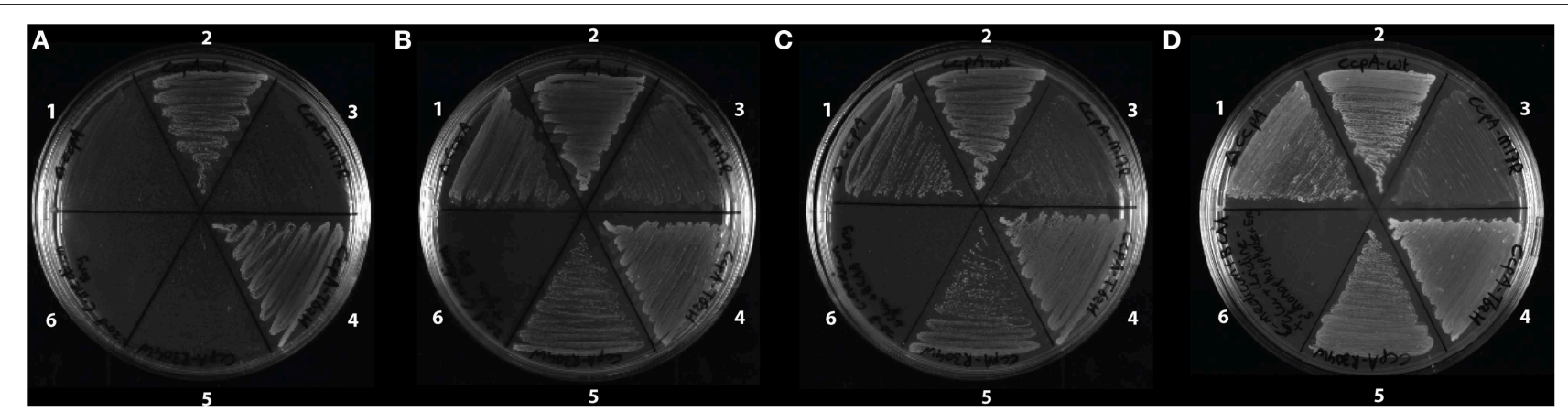

FIGURE 4 | Growth of the strains with the CcpA mutants (A) on C-medium, (B) on C-medium supplemented with glutamate, (C) on C-medium supplemented with glutamate and branched chain amino acids, and (D) on $\mathbf{C}$-medium supplemented with glutamate, branched chain amino acids and uridine $\mathbf{5}^{\prime}$-monophosphate. All strains are B. subtilis ccpA::spec and strain 2-5 have ccpA on a plasmid. 1, $\Delta$ ccpA; 2, ccpAwt; 3, ccpA-M17R; 4, ccpA-T62H; 5, ccpA-R304W; 6, empty.

CcpA-T62H strain still repressed the rocG expression and did not have a growth defect (Figures 4A,B). The growth deficiency of the mutants was almost fully restored to the same extent as CcpA-wt when the C-medium agar plates were supplemented with glutamate, except for CcpA-M17R (Figure 4B) and fully restored when the C-medium agar plates were supplemented with glutamate and branched chain amino acids (BCAA), except for CcpA-M17R (Figure 4C). The growth defect of the CcpAM17R mutant strain was partially restored by the addition of glutamate (Figure 4B); however the addition of only glutamate was not enough. The remaining growth defect of the CcpAM17R strain might be explained by the pyrE gene. PyrE is responsible for pyrimidine biosynthesis (Subtiwiki, 2014) and its gene expression was only down-regulated in the CcpA-M17R strain. This strain did not show a growth defect in LB because $\mathrm{LB}$ is rich in nucleotides from the yeast extract. Therefore the Cmedium was also supplemented with uridine $5^{\prime}$-monophosphate in addition to glutamate and BCAA, but the growth defect of the CcpA-M17R mutant strain was not restored (Figure 4D). The residual growth deficiency remains elusive and is probably dependent on more additives.

\section{Examination of Cre Sites for Analysis of CcpA-M17R}

The methionine on position 17 in CcpA is involved in DNA binding, therefore the sequence of the cre site could play a role in the gene regulation by CcpA-M17R. Unfortunately, not all genes affected by CcpA-M17R could be taken into account, because many genes have no cre site; they are subjected to indirect control by CcpA (Ludwig et al., 2002; Görke and Stülke, 2008; Marciniak et al., 2012). All known cre sites for genes that had an altered regulation in the CcpA-M17R mutant were compared. Genes were grouped into three classes for the analysis; only affected in the $\triangle \mathrm{CcpA}$ strain, affected in both $\triangle \mathrm{CcpA}$ and CcpA-M17R, and only affected in the CcpA-M17R strain. The cre sequences were analyzed for their palindromic nature, but the differences between the groups of cre sites were not clear enough to draw conclusions (see Supplementary File, Sheet 8, Tables 1, 4). Furthermore, the similarity of each group of cre sites to the consensus cre site was compared but there was no significant difference between all three regulatory groups (see Supplementary File, Sheet 8, Tables 1, 4).

Weblogos for the groups of cre sites affected only in CcpAM17R showed that these cre sites had a higher occurrence of $\mathrm{G}$ on position 4 and a less defined nucleotide on position 10 (Supplementary File, Sheet 8, Table 1). The methionine on position 17 was shown to bind to thymine12 in the ackA cre site (Schumacher et al., 2011), and the less defined nucleotide on position 10 found here could mean that the arginine reached further into its surroundings than the methionine.

The consensus cre site is $\mathrm{W}_{1} \mathrm{~T}_{2} \mathrm{G}_{3} \mathrm{~N}_{4} \mathrm{~N}_{5} \mathrm{~A}_{6} \mathrm{R}_{7} \mathrm{C}_{8} \mathrm{G}_{9} \mathrm{~N}_{10} \mathrm{~W}_{11}$ $\mathrm{W}_{12} \mathrm{~W}_{13} \mathrm{C}_{14} \mathrm{~A}_{15} \mathrm{~W}_{16}$ and the $\mathrm{G}_{3}, \mathrm{C}_{8}, \mathrm{G}_{9}, \mathrm{C}_{14}$ are most conserved (Schumacher et al., 2011). Seven of the thirteen genes or operons with a known cre site that were affected by CcpA-M17R also had a $\mathrm{T}$ on position 12 in the cre site, the other six had a $\mathrm{C}(3 \mathrm{x})$, a $\mathrm{G}(2 \mathrm{x})$, or an $\mathrm{A}(1 \mathrm{x})$ on position 12 , but those six had a $\mathrm{T}$ on position $11(5 \mathrm{x})$ or position $13(1 \mathrm{x})$. This finding could mean that the arginine on position 17 in CcpA also contacted a thymine in the cre site and that the longer sidechain of arginine could reach further into the surrounding (Supplementary File, Sheet 8 , Tables 1, 4).

\section{Sensitivity for Extracellular Glucose}

Earlier work shows that the transport of glucose decreases in a CcpA knockout strain (Ludwig et al., 2002). We hypothesize that a decreased glucose uptake would result in a decreased growth rate. The growth rates of the different CcpA strains were examined on $\mathrm{LB}+1 \%$ glucose and the $\triangle \mathrm{CcpA}$, CcpA-M17R, and CcpA-R304W strains grew a little bit slower than the CcpA-wt strain (Supplementary File, Sheet 12), which could be due to a decreased glucose uptake. The growth of the CcpA-T62H strain was the same as the CcpA-wt strain, which could be explained by the strong repressive mode of CcpA-T62H.

None of the pts genes, the glucose permease, or glucose symporter were differently expressed in $L B+1 \%$ glucose or in LB in any of the mutant strains, which means that the uptake of glucose was not regulated at the level of gene expression, as shown before (Singh et al., 2008). 


\section{Discussion}

CcpA is a global regulator of carbon catabolite control in $B$. subtilis and needs HPr or Crh as a coeffector (Moreno et al., 2001; Sonenshein, 2007; Fujita, 2009). It has been previously estimated that there are 150 cre sites in B. subtilis, which are involved in the regulation of around 300 genes (Fujita, 2009). Moreno et al. reported in a genome-wide transcriptome study that about 85 genes are activated by CcpA and 250 genes are repressed by CcpA in LB + glucose medium (Moreno et al., 2001). However, according to the CcpA regulon from SubtiWiki (Mäder et al., 2012; Subtiwiki, 2014) there are only 11 genes activated by CcpA and 202 repressed. The genes mentioned in the SubtiWiki CcpA regulon are probably directly regulated by CcpA; the class 1 genes (Ludwig et al., 2002) and the other genes found by Moreno et al. are probably indirectly regulated; the class 2 genes (Ludwig et al., 2002). Class 1 genes have a cre site and class 2 genes are affected when CcpA alters the glucose uptake (through altered phosphorylation of HPr) and thereby changes the concentration of intracellular inducers (Ludwig et al., 2002; Blencke et al., 2003). There are also class 0 genes, which are independent of CcpA (Ludwig et al., 2002). In a transcriptome study Yoshida et al. have found 66 genes of which the repression was glucose dependent (Yoshida et al., 2001). Here we found 244 genes which had a glucose dependent regulation in one of the CcpA mutant strains (Supplementary File, Sheet 2).

Marciniak et al. (2012) have categorized all known (and predicted) B. subtilis cre sites from high to low affinity. To do so, they have replaced the native $c c p A$ promoter by an inducible promoter, then the fold change in gene expression was examined for a low, medium and high level of $c c p A$ expression. The correlation between the fold change in gene expression and the position of the cre site compared to the transcriptional start site (TSS) was mapped (Marciniak et al., 2012). The information found was used in this transcriptomics study to sort the affected genes on the basis of cre to TSS distance, and check whether it correlated to the fold change in gene expression but there was no clear correlation between fold change and cre to TSS distance. The fold change was very similar over a range of cre to TSS distances (Supplementary File, Sheet 7).

The genes that are controlled by CcpA are in most cases also controlled by a second regulator, which is substrate specific (personal communication with Jörg Stülke). Thus, it is impossible to find the whole CcpA regulon in the $\triangle \mathrm{CcpA}$ experiment. The other genes found in this study that do not belong to SubtiWiki's CcpA regulon could be unidentified members of the CcpA regulon, or a member of the class 2 genes (Ludwig et al., 2002). On the other hand, the CcpA regulon from SubtiWiki contains 213 genes, but 152 of them were not altered in the $\triangle \mathrm{CcpA}$ strain. One explanation for the missing genes from the CcpA regulon from SubtiWiki could be that the list of genes in the CcpA regulon from SubtiWiki is composed from various experiments with various growth conditions, e.g. also from late exponential, or stationary growth phase or in minimal media containing glucose.

18 genes from the CcpA regulon from SubtiWiki were affected both in the presence and absence of glucose; the rbsRKDACB operon for ribose was strongly deregulated in $\mathrm{LB}+1 \%$ glucose and the licHA, $b g l H P$, and $g n t K$ are slightly deregulated in the presence of glucose and the other seven genes were the same in both conditions (Supplementary File, Sheet 11).

The changes in gene regulation in absence of glucose in the $\Delta$ CcpA strain also showed that CcpA was involved in glucose independent gene regulation, as has been shown before (Moreno et al., 2001). Moreno et al. show that those genes are not involved in carbon metabolism (Moreno et al., 2001), but that was not the case in this study. 46 of these 89 genes could be grouped into only four COG-categories: Energy production and conversion [C], Amino acid transport and metabolism [E], Carbohydrate transport and metabolism [G], and Transcription [K] (Figure 3 and Supplementary File, Sheet 10).

The neutral methionine on position 17 in CcpA was changed to a positively charged arginine. The M17R mutation was expected to alter the DNA-binding affinity of CcpA; the positively charged arginine could cause stronger binding to the negatively charged DNA. CcpA-M17R is probably a weaker repressor, because the number of differentially regulated genes was lower than in the $\triangle \mathrm{CcpA}$ strain. All upregulated genes are most likely the result of a weaker repression by CcpA-M17R because CcpA is mainly involved in gene repression. However, it was hard to explain the altered gene regulation by effects on DNA binding, as shown by cre site comparison; there were no clear differences in the cre sites from genes that were only affected in the $\triangle \mathrm{CcpA}$ strain or in the CcpA-M17R strain (Supplementary File, Sheet 8 , Tables 1,4$)$. The palindromicity of the cre sites in the group of genes that was affected by CcpA-M17R was lower than in the group of genes that was only affected by $\triangle \mathrm{CcpA}$; this could indicate that the palindromicity of the cre site is less important for CcpA-M17R.

The CcpA protein consists of a N-terminal DNA binding domain and a core domain for coeffector and HPr binding, linked together with a hinge helix region. The threonine on position 62 is located in the core protein, just above the hingehelix, and is important for the conformational change in the CcpA protein upon HPr binding (Schumacher et al., 2011). This conformational change is believed to improve DNA binding. The threonine to histidine mutation on position 62 has been found during a random mutagenesis study of CcpA-T62, where CcpA$\mathrm{T} 62 \mathrm{H}$ was found to repress $x y n P$ strongly in the absence of glucose (Thesis G. Seidel, Erlangen, Germany, 2005).

We found a large number of down-regulated genes in the CcpA-T62H strain, especially in the absence of glucose. Therefore, we suggest that the CcpA-T62H variant was a stronger repressor than CcpA-wt. The downregulated genes might not be regulated by wildtype CcpA under the chosen conditions. The high number of affected genes in LB without glucose could indicate that the role of $\mathrm{HPr}$-Ser46-P for complex formation was less important for this mutant, since catabolite repression was observed in the absence of glucose. There were only a few genes upregulated in case of CcpA-T62H compared to CcpA-wt and the other mutants. We can conclude that the T62H substitution forces CcpA into a conformational change that happens normally in CcpA upon HPr-Ser46-P binding; this change is probably beneficial for DNA binding. The binding of a CcpA mutant 
protein to cre sites without the prior binding of CcpA to the corepressor HPr-Ser46-P was observed before for five CcpA mutants in B. megaterium (Kuster-Schock et al., 1999).

The most important residue for the interaction of CcpA with HPr-Ser46-P is the arginine at position 304 in CcpA (Sprehe et al., 2007; Schumacher et al., 2011). HPr will be phosphorylated on serine 46 by HPrK/P when glucose is used as a carbon source (Fujita et al., 1995; Görke and Stülke, 2008) and subsequently HPr-Ser46-P will form a complex with CcpA. The formation of this complex stimulates the CcpA-HPr-Ser46-P heterodimer formation needed to bind to DNA (Deutscher et al., 1995; Fujita et al., 1995; Schumacher et al., 2011). The positively charged arginine at position 304 was mutated to the neutral, but bulkier tryptophan which probably made binding of this CcpA mutant to the negatively charged HPr-Ser46-P more difficult.

The large number of genes affected by CcpA-R304W in the presence of glucose suggest $\mathrm{HPr}$ independent gene regulation. There were 234 genes affected by CcpA-R304W in the presence of glucose, 205 genes were affected in the absence of glucose, and 69 genes were affected in both conditions. The rbsRKDACB operon for ribose was strongly deregulated in the $\triangle \mathrm{CcpA}$ strain, but much less deregulated in CcpA-R304W (Supplementary File, Sheet 11) indicating that the repressor function of CcpA-R304W decreased which is probably due to the decreased binding of HPrSer46-P. The large number of genes affected by CcpA-R304W in the absence of glucose also suggest HPr independent gene regulation, because $\mathrm{HPr}$ is not phosphorylated in the absence of glucose so the CcpA-HPr complex formation is reduced but CcpA-R304W is still affecting the regulation of many genes (Table 5, Supplementary File, Sheets 4, 5).

Another explanation could be that the signal transduction in the protein has changed due to the mutation. Maybe the R304W mutation fixes CcpA into the HPr-Ser46-P bound conformation. Or possibly binding of the coeffectors fructose-1,6-bisphosphate (FBP) and glucose-6-phosphate (G6P) is more difficult. Earlier work shows that the affinity of HPr-Ser46-P to CcpA increased more than twofold by the presence of $40 \mathrm{mM}$ FBP or G6P (Seidel et al., 2005), but if coeffector binding is reduced then the affinity of CcpA-R304W to HPr-Ser46-P is also reduced. It will be interesting to measure the binding affinity of CcpA-R304W to HPr-Ser46-P with SPR in a future study.

It is known that a ptsH-S46A strain lost part of its repressing power (Deutscher et al., 1994; Martin-Verstraete et al., 1995) and here we showed that CcpA-R304W also lost part of its ability to repress gene expression. These results show that CcpA and HPr depend on each other and either one of the mutations makes complex formation more difficult.

The regulation of genes in some COGs really differed from CcpA-wt, i.e., they were not regulated by the CcpA-wt but only by the CcpA-mutant. Genes in COGs for Energy production [C], carbohydrate metabolism [G], translation [J], posttranslational modification $[\mathrm{O}]$, and inorganic ion transport $[\mathrm{P}]$ are more strongly repressed in the CcpA-T62H and CcpA-R304W mutants than in the CcpA-wt strain in LB $+1 \%$ glucose (Figure 3 ) which shows the differential regulatory character of the CcpA mutants.

In general, we should take into account that the CcpA mutants studied here could have effects on gene regulation which cannot be seen in LB medium with a CcpA mutant because there might be unknown triggers for CcpA which are absent in $\mathrm{LB} \pm$ glucose. Furthermore, LB medium without added glucose still contains low amounts of glucose and other repressing sugars which might still control the most sensitive target genes. The mutations might uncouple regulation from these triggers. Future experiments in chemically defined medium or in a HPr knockout in the CcpA mutant strains could be done to reveal triggers involved in CcpA dependent gene regulation which were not present when the strains were grown in LB.

In conclusion, the point mutations in $\mathrm{CcpA}$ in this study were made to get more insight into the gene regulation mechanisms of CcpA. The main finding here was that the M17R mutation resulted in a small relief of CCR. CcpA-T62H was a stronger repressor than CcpA-wt and can do CCR also in the absence of glucose. CcpA-R304W had a strong regulatory affect in presence and absence of glucose and we suggest that CcpA-R304W is less dependent on HPr-Ser46-P, FBP, and G6P. However, SPR measurements should show the binding affinity of the CcpA mutants to the cre sites in presence or absence of HPr-Ser46-P.

\section{Funding}

RD and OK were financially supported by a specific SYSMO2 grant from ALW-NWO. GS was financially supported by a specific SYSMO2 grant from the BMBF.

\section{Acknowledgments}

We would like to thank Dr. Maike Bartholomae and Dr. Lance Keller (Molecular Genetics, University of Groningen) for critically reading of the manuscript.

\section{Supplementary Material}

The Supplementary Material for this article can be found online at: http://journal.frontiersin.org/article/10.3389/fmicb. 2015.01051

Supplementary File | CcpAmut sup_INFO_1.xlsx. The titles of the 12 different sheets in the file are listed below. Row 1 in every sheet gives an explanation of the data shown in that sheet. 1_LBgluc_All signif_fold $>1.7$;

2_LBgluc_Venn_diagram_fold $>1.7$; 3_LBgluc_Regulatory_groups;

4_LB_ALLsignif_fold $>1.7$; 5_LB_Venn_diagram_fold $>1.7$;

6_LB_Regulatory_groups; 7_LBgluc_CRE-TSSdistance; 8_cre_palindromicity;

9_LBgluc_COGcat; 10_LB_COGcat; 11_CcpA_regulon; 12_growth curves. 


\section{References}

Arantes, O., and Lereclus, D. (1991). Construction of cloning vectors for Bacillus thuringiensis. Gene 108, 115-119. doi: 10.1016/0378-1119(91) 90495-W

Blencke, H. M., Homuth, G., Ludwig, H., Mäder, U., Hecker, M., and Stülke, J. (2003). Transcriptional profiling of gene expression in response to glucose in Bacillus subtilis: regulation of the central metabolic pathways. Metab. Eng. 5, 133-149. doi: 10.1016/S1096-7176(03)00009-0

Casadaban, M. J., and Cohen, S. N. (1980). Analysis of gene control signals by DNA fusion and cloning in Escherichia coli. J. Mol. Biol. 138, 179-207. doi: 10.1016/0022-2836(80)90283-1

Detert Oude Weme, R. G., Kovacs, A. T., de Jong, S. J., Veening, J. W., Siebring, J., and Kuipers, O. P. (2015). Single cell FRET analysis for the identification of optimal FRET-pairs in Bacillus subtilis using a prototype MEM-FLIM system. PLoS ONE 10:e0123239 doi: 10.1371/journal.pone.01 23239

Deutscher, J. (2008). The mechanisms of carbon catabolite repression in bacteria. Curr. Opin. Microbiol. 11, 87-93. doi: 10.1016/j.mib.2008. 02.007

Deutscher, J., Kuster, E., Bergstedt, U., Charrier, V., and Hillen, W. (1995). Protein kinase-dependent $\mathrm{HPr} / \mathrm{CcpA}$ interaction links glycolytic activity to carbon catabolite repression in gram-positive bacteria. Mol. Microbiol. 15, 1049-1053. doi: 10.1111/j.1365-2958.1995.tb02280.x

Deutscher, J., Reizer, J., Fischer, C., Galinier, A., Saier, M. H. Jr., and Steinmetz, M. (1994). Loss of protein kinase-catalyzed phosphorylation of HPr, a phosphocarrier protein of the phosphotransferase system, by mutation of the ptsH gene confers catabolite repression resistance to several catabolic genes of Bacillus subtilis. J. Bacteriol. 176, 3336-3344.

Faires, N., Tobisch, S., Bachem, S., Martin-Verstraete, I., Hecker, M., and Stülke, J. (1999). The catabolite control protein CcpA controls ammonium assimilation in Bacillus subtilis. J. Mol. Microbiol. Biotechnol. 1, 141-148.

Fujita, Y. (2009). Carbon catabolite control of the metabolic network in Bacillus subtilis. Biosci. Biotechnol. Biochem. 73, 245-259. doi: 10.1271/bbb. 80479

Fujita, Y., Miwa, Y., Galinier, A., and Deutscher, J. (1995). Specific recognition of the Bacillus subtilis gnt cis-acting catabolite-responsive element by a protein complex formed between CcpA and seryl-phosphorylated HPr. Mol. Microbiol. 17, 953-960. doi: 10.1111/j.1365-2958.1995.mmi_1705 0953.x

Görke, B., and Stülke, J. (2008). Carbon catabolite repression in bacteria: many ways to make the most out of nutrients. Nat. Rev. Microbiol. 6, 613-624. doi: 10.1038/nrmicro1932

Harwood, C. R., and Cutting, S. M. (1990). "Growth, maintenance and general techniques. Chapter 1 and appendix 1," in Molecular Biological Methods for Bacillus, eds C. R. Harwood and S. M. Cutting (Chichester: John Wiley \& Sons, Inc), 1-23; 545-550.

Henkin, T. M., Grundy, F. J., Nicholson, W. L., and Chambliss, G. H. (1991). Catabolite repression of alpha-amylase gene expression in Bacillus subtilis involves a trans-acting gene product homologous to the Escherichia coli lacl and galR repressors. Mol. Microbiol. 5, 575-584. doi: 10.1111/j.13652958.1991.tb00728.x

Horstmann, N., Seidel, G., Aung-Hilbrich, L. M., and Hillen, W. (2007). Residues His-15 and Arg-17 of HPr participate differently in catabolite signal processing via CcpA. J. Biol. Chem. 282, 1175-1182. doi: 10.1074/jbc.m6058 54200

Kuster, E., Luesink, E. J., de Vos, W. M., and Hillen, W. (1996). Immunological crossreactivity to the catabolite control protein CcpA Bacillus megaterium is found in many gram-positive bacteria. FEMS Microbiol. Lett. 139, 109-115. doi: 10.1016/0378-1097(96)00126-7

Kuster-Schock, E., Wagner, A., Volker, U., and Hillen, W. (1999). Mutations in catabolite control protein CcpA showing glucose-independent regulation in Bacillus megaterium. J. Bacteriol. 181, 7634-7638.

Long, A. D., Mangalam, H. J., Chan, B. Y., Tolleri, L., Hatfield, G. W., and Baldi, P. (2001). Improved statistical inference from DNA microarray data using analysis of variance and a Bayesian statistical framework. Analysis of global gene expression in Escherichia coli K12. J. Biol. Chem. 276, 19937-19944. doi: 10.1074/jbc.M010192200
Ludwig, H., Rebhan, N., Blencke, H. M., Merzbacher, M., and Stülke, J. (2002). Control of the glycolytic gapA operon by the catabolite control protein A in Bacillus subtilis: a novel mechanism of CcpA-mediated regulation. Mol. Microbiol. 45, 543-553. doi: 10.1046/j.1365-2958.2002. 03034.x

Lulko, A. T., Buist, G., Kok, J., and Kuipers, O. P. (2007). Transcriptome analysis of temporal regulation of carbon metabolism by CcpA in Bacillus subtilis reveals additional target genes. J. Mol. Microbiol. Biotechnol. 12, 82-95. doi: $10.1159 / 000096463$

Mäder, U., Schmeisky, A. G., Florez, L. A., and Stülke, J. (2012). SubtiWikia comprehensive community resource for the model organism Bacillus subtilis. Nucleic Acids Res. 40, D1278-D1287. doi: 10.1093/nar/ gkr923

Marciniak, B. C., Pabijaniak, M., de Jong, A., Duhring, R., Seidel, G., Hillen, W., et al. (2012). High- and low-affinity cre boxes for CcpA binding in Bacillus subtilis revealed by genome-wide analysis. BMC Genomics 13:401. doi: 10.1186/1471-2164-13-401

Martin-Verstraete, I., Stülke, J., Klier, A., and Rapoport, G. (1995). Two different mechanisms mediate catabolite repression of the Bacillus subtilis levanase operon. J. Bacteriol. 177, 6919-6927.

Miwa, Y., Nakata, A., Ogiwara, A., Yamamoto, M., and Fujita, Y. (2000). Evaluation and characterization of catabolite-responsive elements (cre) of Bacillus subtilis. Nucleic Acids Res. 28, 1206-1210. doi: 10.1093/nar/28. 5.1206

Moreno, M. S., Schneider, B. L., Maile, R. R., Weyler, W., and Saier, M. H. Jr. (2001). Catabolite repression mediated by the CcpA protein in Bacillus subtilis: novel modes of regulation revealed by whole-genome analyses. Mol. Microbiol. 39, 1366-1381. doi: 10.1111/j.1365-2958.2001.02328.x

Norholm, M. H. (2010). A mutant Pfu DNA polymerase designed for advanced uracil-excision DNA engineering. BMC Biotechnol. 10:21. doi: 10.1186/14726750-10-21

Sambrook, J., Fritsch, E. F., and Maniatis, T. (1989). Molecular Cloning: A Laboratory Manual. NewYork, NY: Cold Spring Harbor Laboratory Press.

Schumacher, M. A., Seidel, G., Hillen, W., and Brennan, R. G. (2006). Phosphoprotein Crh-Ser46-P displays altered binding to CcpA to effect carbon catabolite regulation. J. Biol. Chem. 281, 6793-6800. doi: 10.1074/jbc.m509977200

Schumacher, M. A., Seidel, G., Hillen, W., and Brennan, R. G. (2007). Structural mechanism for the fine-tuning of CcpA function by the small molecule effectors glucose 6-phosphate and fructose 1,6-bisphosphate. J. Mol. Biol. 368, 1042-1050. doi: 10.1016/j.jmb.2007.02.054

Schumacher, M. A., Sprehe, M., Bartholomae, M., Hillen, W., and Brennan, R. G. (2011). Structures of carbon catabolite protein A-(HPr-Ser46-P) bound to diverse catabolite response element sites reveal the basis for high-affinity binding to degenerate DNA operators. Nucleic Acids Res. 39, 2931-2942. doi: 10.1093/nar/gkq1177

Seidel, G., Diel, M., Fuchsbauer, N., and Hillen, W. (2005). Quantitative interdependence of coeffectors, $\mathrm{CcpA}$ and cre in carbon catabolite regulation of Bacillus subtilis. FEBS J. 272, 2566-2577. doi: 10.1111/j.1742-4658.2005. 04682.x

Singh, K. D., Schmalisch, M. H., Stülke, J., and Görke, B. (2008). Carbon catabolite repression in Bacillus subtilis: quantitative analysis of repression exerted by different carbon sources. J. Bacteriol. 190, 7275-7284. doi: 10.1128/jb.00 848-08

Sonenshein, A. L. (2007). Control of key metabolic intersections in Bacillus subtilis. Nat. Rev. Microbiol. 5, 917-927. doi: 10.1038/nrmicro1772

Sprehe, M., Seidel, G., Diel, M., and Hillen, W. (2007). CcpA mutants with differential activities in Bacillus subtilis. J. Mol. Microbiol. Biotechnol. 12, 96-105. doi: 10.1159/000096464

Stülke, J., and Hillen, W. (2000). Regulation of carbon catabolism in Bacillus species. Аnnu. Rev. Microbiol. 54, 849-880. doi: 10.1146/annurev.micro.54.1.849

Subtiwiki (2014). CcpA Regulon. Available online at: http://subtiwiki.unigoettingen.de/wiki/index.php/CcpA_regulon 2014

van Hijum, S. A., de Jong, A., Baerends, R. J., Karsens, H. A., Kramer, N. E., Larsen, R., et al. (2005). A generally applicable validation scheme for the assessment of factors involved in reproducibility and quality of DNA-microarray data. BMC Genomics 6:77. doi: 10.1186/1471-2164-6-77 
van Hijum, S. A., Garcia de la Nava, J., Trelles, O., Kok, J., and Kuipers, O. P. (2003). MicroPreP: a cDNA microarray data pre-processing framework. Appl. Bioinformatics 2, 241-244.

Yoshida, K., Kobayashi, K., Miwa, Y., Kang, C. M., Matsunaga, M., Yamaguchi, H., Tojo, S., et al. (2001). Combined transcriptome and proteome analysis as a powerful approach to study genes under glucose repression in Bacillus subtilis. Nucleic Acids Res. 29, 683-692. doi: 10.1093/nar/29.3.683

Zeigler, D. R., Pragai, Z., Rodriguez, S., Chevreux, B., Muffler, A., Albert, T., et al. (2008). The origins of 168, W23, and other Bacillus subtilis legacy strains. J. Bacteriol. 190, 6983-6995. doi: 10.1128/jb.00722-08
Conflict of Interest Statement: The authors declare that the research was conducted in the absence of any commercial or financial relationships that could be construed as a potential conflict of interest.

Copyright (c) 2015 Detert Oude Weme, Seidel and Kuipers. This is an open-access article distributed under the terms of the Creative Commons Attribution License (CC $B Y)$. The use, distribution or reproduction in other forums is permitted, provided the original author(s) or licensor are credited and that the original publication in this journal is cited, in accordance with accepted academic practice. No use, distribution or reproduction is permitted which does not comply with these terms. 